\title{
Papel de la proteína supresora de la señalización por citocinas-3 (SOCS 3) en la resistencia a la hormona de crecimiento inducida por malnutrición
}

\begin{abstract}
Adriana Umaña, Stella Carrasco, Myriam Sánchez
Departamento de Química, Facultad de Ciencias, Universidad Nacional de Colombia, Bogotá, D.C., Colombia.

La nutrición es un regulador importante de las acciones de la hormona de crecimiento (GH). Se ha demostrado que el déficit de nutrientes induce un estado de resistencia a la hormona, en el cual están involucrados, entre otros factores, alteraciones post-receptor en la vía de señalización, pero se desconocen los mecanismos responsables. En este trabajo se investigó la participación de algunos miembros de la familia de proteínas supresoras de la señalización por citocinas (SOCS) en la resistencia causada por malnutrición, que inhibe la activación de la señalización a través de Janus cinasa 2/transductor de señal y activador de la transcripción 5 (JK2/STAT5). Se estudiaron los cambios en la expresión génica del receptor de $\mathrm{GH}(\mathrm{RGH})$, IGF-I y SOCS3 en el hígado de ratas alimentadas con una dieta baja en proteína (8\%) y estimuladas con $\mathrm{GH}$. La restricción en el consumo de proteína disminuyó significativamente $(p<0,05)$ los contenidos de ARNm del RGH al igual que el número de sitios receptores, pero elevó significativamente $(p<0,05)$ la transcripción del gen SOCS3. La administración de hormona de crecimiento humana recombinante $(\mathrm{rhGH})$ a ratas restringidas en proteína incrementó los niveles del mensajero del RGH y del IGF-I, pero sólo para el primero se lograron restablecer valores comparables a los de animales alimentados con una dieta alta en proteína (20\%). La transcripción de SOCS3 en el grupo malnutrido se incrementó aún más como resultado de la administración de $\mathrm{GH}$. En resumen, los resultados obtenidos sugieren que la reducción en la sensibilidad del tejido hepático a la GH que acompaña la malnutrición puede deberse en parte a una sobreexpresión de la proteína SOCS3. Además, la distribución ubicua de SOCS3 y CIS plantea un papel más amplio de las proteínas SOCS como reguladoras de la sensibilidad de los tejidos a las citocinas.
\end{abstract}

Palabras clave: hormona de crecimiento, SOCS, malnutrición, hormonas.

Role of suppressor of cytokine signaling proteins in growth hormone resistance induced by malnutrition

Nutrition is an important regulator of growth hormone $(\mathrm{GH})$ action. Nutritional deprivation causes a GH resistance involving post-receptor alterations in the signaling pathway, but the responsible mechanisms remain unknown. Herein, suppressors of cytokine signaling proteins (SOCS) were investigated as potential agents in $\mathrm{GH}$-resistance induced by malnutrition which inhibits activation of Janus kinase 2/signal transductor and activator of transcription 5 (JAK2/STAT5) pathway. Growth hormone receptor (GHR), IGF-I and SOCS3 mRNA expression was meassured in the liver of rats fed with a low protein diet and with $\mathrm{GH}$ stimulation. Protein diet restriction significantly diminished GHR mRNA and receptor binding sites $(p<0.05)$, but caused a highly increased SOCS3 gene expression. In diet-restricted rats, GH administration increased GHR and IGF-I mRNA; however, GHR reached basal levels observed in animals feeding with a high protein diet. The malnourished group increased SOCS3 gene transcription in response to $\mathrm{GH}$ administration. These results suggested that a reduced hepatic sensitivity to $\mathrm{GH}$ was associated with SOCS3 over-expression. In addition, ubiquitous distribution of SOCS3 and CIS suggests a role for SOCS proteins as tissue specific modulators of cytokine sensitivity.

Key words: growth hormone, suppressor of cytokine signaling proteins, malnutrition, hormones. 
La hormona de crecimiento (GH) tiene diversos efectos en el crecimiento y metabolismo, resultado de acciones directas sobre la expresión génica o indirectas a través del factor de crecimiento similar a la insulina tipo I (IGF-I) (1). La GH se enlaza a su receptor en la superficie celular provocando su dimerización y activación a través de la tirosina cinasa JAK2. Esta cascada de señalización genera la fosforilación de las proteínas transductoras de la señal y activadoras de la transcripción (STAT) en respuesta al complejo receptor JAK2 fosforilado. Estas proteínas forman homo o heterodímeros y se translocan al núcleo, donde estimulan la transcripción de genes activados por $\mathrm{GH}(2,3)$.

Por otra parte, el dimorfismo sexual es una característica del desempeño fisiológico de la hormona. Mientras en machos existe un patrón de pulsatilidad con máximos cada 2 a 3 horas, en el caso de las hembras la secreción tiene menor variación (4). El patrón de secreción pulsátil es posible si se cuenta con un sistema apropiado para la rápida desensibilización de la señal. En concordancia con esta necesidad, se han postulado diferentes mecanismos de inactivación de la señalización, entre ellos, la inhibición por fosfatasas (5), la degradación de intermediarios por el proteosoma (6) y, más recientemente, por proteínas supresoras de la señalización por citocinas (SOCS) (7), cuyos mecanismos de inhibición aún no han sido totalmente establecidos.

Los efectos de la GH se pueden ver alterados en algunos estados como la malnutrición (8). Un fenómeno bien conocido es la resistencia a la acción de la GH que acompaña a la desnutrición, aunque los mecanismos responsables de su inducción no han sido establecidos. Recientemente se ha sugerido que las proteínas SOCS, como reguladores negativos, pueden reducir la sensibilidad de los tejidos a las hormonas y contribuir a la resistencia hormonal (9).

\footnotetext{
Correspondencia:

Laboratorio de Hormonas, Departamento de Química, Facultad de Ciencias, Universidad Nacional de Colombia. Teléfono: 3165000 Ext 14466. Fax: 3165220.

yumana@ciencias.ciencias.unal.edu.co

Recibido: 03/03/03; aceptado: 1/07/03
}

El objetivo del presente estudio fue investigar el papel de las proteínas SOCS en la resistencia a GH generada por malnutrición mediante el examen de los cambios en el estado de expresión de los genes del receptor de GH, IGF-I y SOCS3 en el hígado de ratas que fueron alimentadas con una dieta alta en proteína y con otra deficiente en proteína.

\section{Materiales y métodos}

\section{Animales}

Se utilizaron ratas hembras Sprague Dawley $(n=32)$ de seis semanas de edad (Alab, Estocolmo, Suecia) mantenidas bajo condiciones estándar de luz $(12 \mathrm{~h})$, temperatura $\left(22 \pm 2^{\circ} \mathrm{C}\right)$ y humedad relativa $(67 \%)$, con libre acceso al agua y alimento.

\section{Diseño experimental}

Los animales se asignaron al azar en dos grupos $(n=16)$, después de un período de adaptación de 7 días, un grupo recibió una dieta alta en proteína $(20 \%)(A P)$ y el otro se alimentó con una dieta baja en proteína (8\%) (BP). Las dietas fueron isocalóricas con una energía y composición descrita previamente (10). Cada uno de los grupos se dividió aleatoriamente en dos subgrupos, a los cuales se administró solución salina ( $9 \mathrm{~g} \mathrm{NaCl} / \mathrm{l})$ $u$ hormona de crecimiento humana recombinante ( $r$ hGH, Genotropin $\AA$, Suecia) en una dosis de 360 $\mathrm{mg} /$ día durante 14 días a través de minibombas osmóticas.

Las ratas fueron sacrificadas por asfixia con $\mathrm{CO}_{2}$. La sangre fue recolectada en tubos de vidrio, luego centrifugada ( $2.500 \mathrm{rpm}, 10$ minutos, $4^{\circ} \mathrm{C}$ ) y el suero resultante fue almacenado a $-20^{\circ} \mathrm{C}$ hasta su análisis. El hígado fue extraido y recogido inmediatamente en nitrógeno líquido y almacenado a $-70{ }^{\circ} \mathrm{C}$. El procedimiento experimental se desarrolló de acuerdo con las consideraciones y guías éticas para trabajo con animales en experimentación del Comité de Ética de Pharmacia, Suecia $(10,11)$.

\section{Cuantificación de IGF-I}

EI IGF-I proveniente del hígado se extrajo mediante homogenización del tejido con $5 \mathrm{ml}$ de solución de extracción (ácido acético al 5\%, 
aprotinina $1 \mu \mathrm{g} / \mathrm{ml}$ ) por gramo de tejido. El extracto fue centrifugado, luego se recuperó la fracción sobrenadante, la cual se liofilizó para una posterior reconstitución con $100 \mu$ l de agua destilada antes de la cuantificación del péptido. El IGF-I total en suero y tejido se determinó por radioinmunoanálisis, con previa extracción ácido-etanólica de las proteínas de unión a IGF (12). En el ensayo se usó un anticuerpo policlonal contra IGF-I (Gropep, Adelaide, Australia) y como estándar IGFI recombinante humano (rhIGF-I, Pharmacia, Suecia). Para evitar la interferencia con las proteínas de unión remanentes de la extracción, se utilizó como trazador I $^{125}$-des(1-3) IGF-I (Pharmacia, Suecia).

\section{Determinación del contenido de receptores de GH (RGH)}

Las muestras de hígado se lavaron en solución de sacarosa $0,25 \mathrm{M}$, se homogenizó $1 \mathrm{~g}$ de tejido en 1 volumen de sacarosa, se centrifugó a $650 \mathrm{~g}$ durante 10 minutos a $4^{\circ} \mathrm{C}$. El sobrenadante se centrifugó a $17.000 \mathrm{~g}$ por 30 minutos. El nuevo sobrenadante se incubó con $\mathrm{NaCl} 0,1 \mathrm{M} / \mathrm{MgSO}_{4} 1$ $\mathrm{mM}(0,24 \mathrm{ml} / 10 \mathrm{ml}$ solución) durante 10 minutos a temperatura ambiente y luego se centrifugó a $37.000 \mathrm{~g}$ por 1 hora para obtener la fracción correspondiente a la membrana. Este residuo se resuspendió en solución tamponada de ensayo (Tris- $\mathrm{HCl} 0,05 \mathrm{M} \mathrm{pH} 7,4$, albúmina sérica humana al 1\%), se homogenizó y se guardó en fracciones a $-70{ }^{\circ} \mathrm{C}$ hasta su análisis (11). A la preparación membranal se le determinó el contenido de proteína por el método de Bradford (13).

Los sitios de enlace a la hormona se determinaron usando como ligando rhGH marcada con Na ${ }^{125}$ por el método de cloramina $\mathrm{T}$ (14) y las membranas de hígado como preparación del receptor. En el ensayo se incubaron $100 \mu$ le trazador $\left(I^{125} \mathrm{rhGH}\right.$ $0,12 \mathrm{nM}, 70 \mathrm{mCi} / \mathrm{mg}), 100 \mu \mathrm{l}$ de $\mathrm{rhGH}$ sin marcar $(0,17-22 \mathrm{nM})$ y $100 \mu \mathrm{l}$ de extracto de membrana hepática en tres diferentes concentraciones $(0,1$, 0,2 y $0,4 \mathrm{mg}$ proteína). El enlace total fue determinado colocando $100 \mu \mathrm{l}$ de solución tamponada de ensayo, el trazador y la membrana. Se incubó a $20^{\circ} \mathrm{C}$ durante $16-20$ horas con agitación continua, luego se adicionaron $750 \mu$ l de solución tamponada de ensayo, y se centrifugó a $5.000 \mathrm{~g}$ por 15 minutos. El residuo resultante se lavó y se centrifugó y su radioactividad fue determinada en un contador gamma (Wallac, Wizard 1400). Los datos fueron analizados mediante el análisis de Scatchard (programa LIGAND) (15).

\section{Cuantificación de ARN mensajero por hibridización en solución}

Para la extracción de los ácidos nucleicos del hígado se usó TRIZOL Reagent (Life Technologies), el cual utiliza una solución monofásica de fenol e isocianato de guanidinio basado en la extracción clásica de Chomczynski y Sacchi (16). El ADN total extraido se cuantificó por el método fluorométrico de Labarca y Paigen (17) y el ARN mediante lecturas de absorbancia a $260 \mathrm{~nm}$.

Los niveles de ARN mensajero de los diferentes genes se midieron en las muestras de ARN total usando el ensayo de protección a ARNasas $(11,18,19)$. Esta metodología permite la cuantificación de ARN mensajeros específicos a través de sondas de ARN sintetizadas por transcripción in vitro. Brevemente, el ARN se incuba con la ribosonda radioactiva ( $\mathrm{S}^{35}$-UTP) durante 18 a 22 horas bajo condiciones estandarizadas para cada una de ellas; posteriormente, esta solución se trata con ribonucleasas durante 45 minutos $\mathrm{y}$, una vez realizada la digestión, el producto es precipitado con ácido tricloroacético y recolectado en filtros de fibra de vidrio (Whatman GF/C). La radioactividad leída en un contador de centelleo líquido (Beckman LS500TD) se compara con una curva estándar de cantidades conocidas de ARN sintetizado in vitro. Para la detección de transcritos de RGH, se empleó una sonda de 539 pares de bases dirigida a la región extramembranal del receptor (exones 2-7) (20); para IGF-I, una sonda de $231 \mathrm{pb}$ que codifica la proteína madura (exón 3) (21); para SOCS3, fragmento de 209 pb que reconoce toda la proteína (22). La especificidad en la inducción de los genes se verificó utilizando como control una sonda de 316 pb para GAPDH (exones 5-8; Ambion Inc., USA).

\section{Análisis estadístico}

Los datos fueron sometidos a análisis de varianza de una vía (ANOVA), teniendo en cuenta la prueba 
de Bartlett para homogeneidad de varianzas. Los valores se consideraron estadísticamente diferentes cuando $p<0,05$.

\section{Resultados}

\section{Niveles circulantes de IGF-I}

En el día 14 del experimento, los animales control que recibieron una dieta baja en proteína mostraron una reducción significativa $(p<0,05)$ en el IGF-I sérico comparado con los valores iniciales (cuadro 1) y la infusión de rhGH no condujo a un incremento de dichos niveles. En las ratas alimentadas con dieta alta en proteína, los niveles circulantes de IGF-I se mantuvieron constantes a través del tratamiento.

\section{Efecto de la proteína de la dieta sobre el eje GH/IGF-I}

Con el fin de determinar el papel de la restricción proteica en la señalización de GH, estudiamos el efecto sobre el receptor de $\mathrm{GH}$, cuya activación da inicio a la cascada de señalización (2). La disminución del contenido de proteína en la dieta redujo los niveles del mensajero de $\mathrm{RGH}$ y la infusión continua de GH los incrementó hasta los niveles basales observados en una dieta alta en proteína (figura 1a).

El análisis de la proteína mostró una reducción significativa $(p<0,05)$ en el número de receptores de $\mathrm{GH}$ como resultado de la restricción proteica. De manera similar, el tratamiento con $\mathrm{rhGH}$ incrementó de forma significativa $(p<0,05)$ el número de sitios de enlace en los animales de los dos esquemas nutricionales (figura $1 \mathrm{~b}$ ).

\section{Expresión de IGF-I en hígado}

La expresión del ARN mensajero del IGF-I se vio afectada significativamente por el consumo de la
A
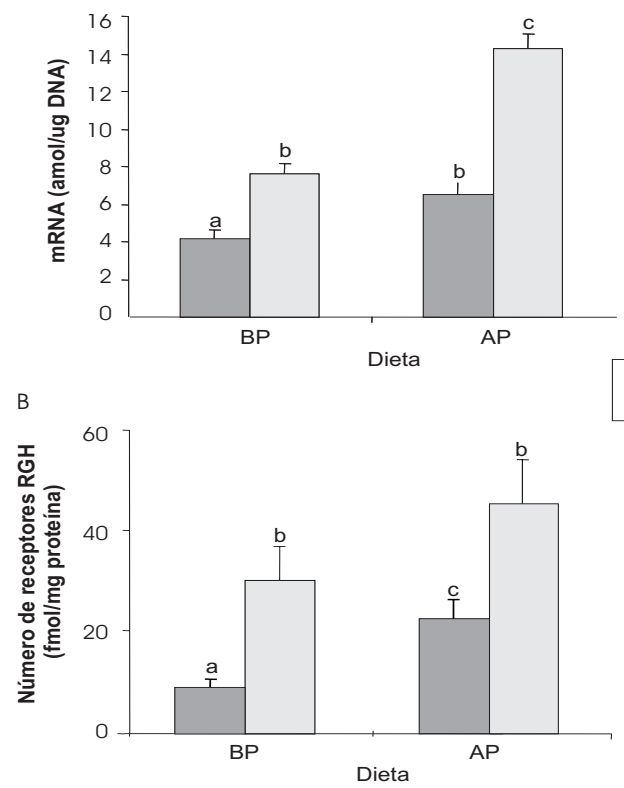

Figura 1. Efecto de la infusión continua de solución salina o rhGH sobre los niveles de $A R N m$ de $R G H$ en el hígado $(A)$ y número de $\mathrm{RGH}(\mathrm{B})$ en ratas alimentadas con baja proteína (BP) y alta proteína (AP) durante 14 días. Los valores corresponden al promedio de 8 animales y las cotas representan la desviación estándar. Las barras que no comparten la misma letra son estadísticamente diferentes $(p<0,05)$.

dieta baja en proteína (8\%), tal como se ha informado en otros casos (23). Sin embargo, el tratamiento con rhGH recuperó los niveles del mensajero en el hígado de estos animales (figura 2a). Al analizar el contenido de péptido se encontró un valor significativamente $(p<0,05)$ más bajo en el grupo restringido, pero en contraste con lo observado con el mensajero, la infusión de rhGH no resultó en una elevación de la concentración de IGF-I (figura 2b).

Cuadro 1. Concentración de IGF-I (ng/ml) en suero de ratas sometidas a consumo de baja proteína (BP) o alta proteína (AP) con infusión continua de solución salina o rhGH.

\begin{tabular}{lccccc}
\hline Dieta & \multicolumn{2}{c}{ AP } & & \multicolumn{2}{c}{ BP } \\
\cline { 2 - 3 } \cline { 5 - 6 } & Promedio & DE & & Promedio & DE \\
\hline Antes del tratamiento (día 0) & 554 & 127 & & 652 & 131 \\
Después del tratamiento (día 14) & & & & $356^{*}$ & 32 \\
$\quad$ Salina & 575 & 50 & & $385^{*}$ & 31 \\
rhGH & 516 & 30 & & & \\
\hline
\end{tabular}

Los valores promedio fueron significativamente diferentes de los valores al día $0,(n=8){ }^{*} p<0,05$. 


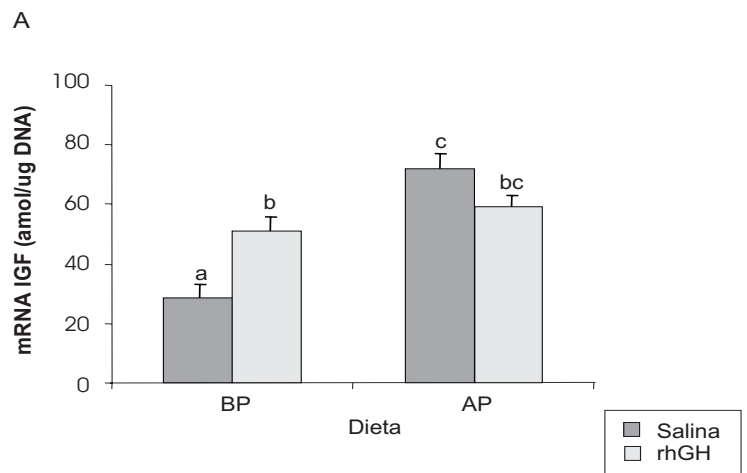

B

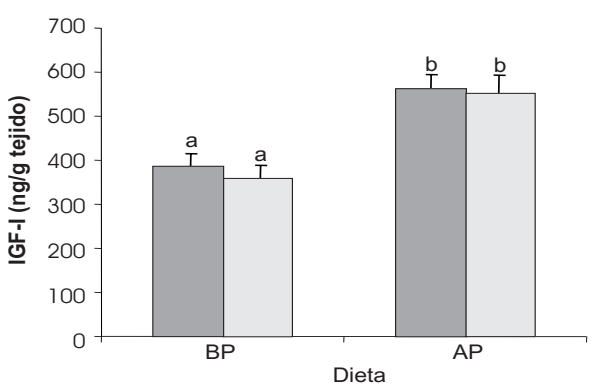

Figura 2. Efecto de la infusión continua de solución salina ( $\square$ ) o rhGH ( $\square$ )en los niveles de ARNm de IGF-I (A) y en la concentración de IGF-I (B) en hígado de ratas alimentadas con baja proteína (BP) y alta proteína (AP), después de un período de 14 días. Los valores corresponden al promedio de 8 animales y las cotas representan la desviación estándar. Las barras que no comparten la misma letra son estadísticamente diferentes $(p<0,05)$.

\section{Regulación de la expresión del gen SOCS3 por la GH y la proteína de la dieta}

Los animales alimentados con la dieta baja en proteína (8\%) y que recibieron la infusión salina presentaron contenidos de ARNm de SOCS3 hepático significativamente $(p<0,05)$ mayores en comparación con los animales del grupo salino de alta proteína (figura 3), lo cual indica que la restricción nutricional va acompañada de una elevación en la transcripción del gen SOCS3 en hígado. El efecto de la administración de GH elevó aún más dichos valores en los dos grupos experimentales.

La expresión del gen GADPH no se vio alterada por la deficiencia nutricional o el tratamiento con rhGH, lo que nos permitió corroborar que los cambios observados en la expresión génica de IGF-I, RGH y SOCS3 fueron específicos de los tratamientos utilizados.

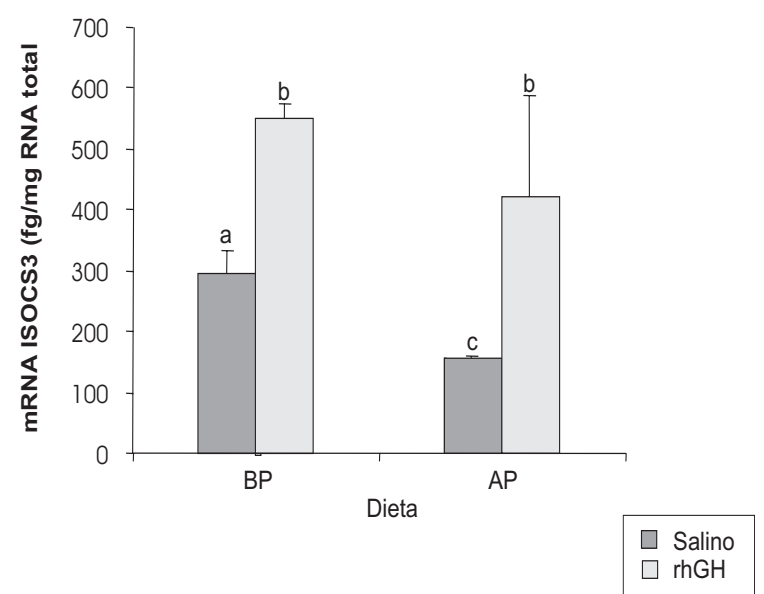

Figura 3. Efecto de la infusión continua de $\mathrm{GH}$ en los niveles de ARNm de SOCS3 en hígado de ratas alimentadas con una dieta alta (AP) o baja (BP) en proteína. Los valores corresponden al promedio de tres datos y las barras que no comparten la misma letra, son estadísticamente diferentes $(p<0,05)$.

\section{Discusión}

La hormona de crecimiento ejerce efectos anabólicos sobre las proteínas (24) al igual que el IGF-I, aunque esta acción es más variable (25) y dependiente del suministro adecuado de aminoácidos (26). La nutrición es, por tanto, un factor determinante para el desarrollo correcto de las funciones del eje GH/IGF-I. En humanos, la desnutrición crónica o el ayuno prolongado entre 7 y 10 días (27) disminuye hasta 20\% la concentración sérica de IGF-I y, paradójicamente, los niveles de GH son normales o elevados. Esta condición se conoce como un estado de resistencia a la acción de la hormona. Varios estudios han permitido establecer que la resistencia a GH es el resultado de la contribución de cambios a nivel del receptor membranal, así como también de defectos post-receptor, pero los mecanismos moleculares aún no han sido claramente establecidos.

Utilizando la rata como modelo experimental, encontramos en un estudio previo (10) que la restricción en proteína durante 14 días produce una disminución del crecimiento corporal, evaluado como la atenuación en la ganancia de peso asociado con una disminución en el consumo y balance total de nitrógeno. En el presente trabajo se encontró que, además del descenso en los 
niveles de IGF-I circulante, la restricción disminuyó de manera significativa el contenido de ARNm del receptor y el número de sitios de enlace $\mathrm{a} \mathrm{GH}$ en el hígado. Se ha descrito que restricciones durante períodos más cortos al empleado en el presente estudio no alteran la capacidad de unión a GH a pesar de los niveles disminuidos del receptor $(28,29)$.

Se ha establecido que los efectos in vivo de la hormona de crecimiento dependen de la forma de administración. Las inyecciones son más efectivas para estimular el crecimiento somático, por su semejanza con el patrón de secreción pulsátil; en tanto que, la administración continua de la hormona incrementa las concentraciones de IGF-I sérico en ratas hipofisectomizadas, pero no en ratas desnutridas (30). Un resultado similar se obtuvo en las condiciones experimentales del presente estudio. La infusión de la hormona de crecimiento a ratas desnutridas no elevó el IGF-I circulante, no obstante, estimuló la transcripción del gen IGFI hepático, pero el contenido tisular del péptido permaneció sin cambio. Estudios previos han mostrado que cuando el suministro de proteína de la dieta se reduce, se bloquean algunos de los mecanismos involucrados en la traducción del gen IGF-I (31-33). Así mismo, se disminuye el tamaño promedio de los polisomas con el consecuente efecto sobre la eficiencia de la traducción (34, 35). La estabilidad del mRNA de IGF-I también puede ser alterada a causa del déficit de proteína. Por tanto, es posible que dichos cambios postranscripcionales expliquen el descenso en los niveles de IGF-I observados en este trabajo. En la mayoría de los casos, la realimentación normaliza los niveles de IGF-I en suero (36), siendo el contenido y calidad de la proteína factores decisivos en el mantenimiento del balance de nitrógeno.

El presente estudio mostró que la rhGH permite restaurar los niveles normales de expresión del receptor en hígado y se logra un incremento en la transcripción local de IGF-I, sin alcanzar un nivel comparable al de los controles. Esta situación se puede interpretar como un estado de resistencia a la acción de la $\mathrm{GH}$, por un defecto post-receptor inducido por el déficit de proteína. El hecho de que el número de receptores hepáticos en los animales de la dieta de bajo contenido proteico, después de recibir la rhGH, sea similar al número de receptores en la dieta normal está indicando que en condiciones de déficit nutricional las células responden movilizando y reorganizando los receptores en su superficie para preservar la homeostasis del tejido. Por tanto, es probable que la disminución en IGF-I no se deba a la pérdida de receptores sino a un defecto post-receptor.

Un punto clave en la transducción de la señal es la desensibilización mediada por el ligando y una inhibición por retroalimentacion, que limitan la intensidad y duración de la señal, lo cual evita las consecuencias inapropiadas de una excesiva respuesta celular. Por tanto, una posible explicación al fenómeno de resistencia hormonal puede ser la alteración de las interacciones proteína-proteína durante la retroalimentación negativa de la señalización intracelular.

En concordancia con lo anterior, las proteínas SOCS han sido identificadas por su capacidad para inhibir la señalización iniciada por citocinas (37-39) y se ha sugerido que actúan mediante un mecanismo clásico de retroalimentacion negativa para terminar la señal $(40,41)$. Esta familia de inhibidores de la señalización (SOCS 1 al 7 y CIS) son inducidos por citocinas que activan la vía JAK/STAT y, aunque su acción reguladora es el resultado del enlace a las proteínas JAK activadas o al receptor para inhibir la unión de STAT a su sitio de anclaje en el receptor fosforilado, los mecanismos exactos de inhibición están por esclarecerse.

La hormona de crecimiento induce la expresión de, al menos, tres de estos genes (SOCS3, SOCS2 y CIS) en diferentes tejidos $(7,42)$, mostrando, además, que la acción de la GH es controlada por la sobreexpresión de estos genes. Así, la sobreexpresión de SOCS3 observada en los hígados de ratas desnutridas puede ser la causa del fenómeno de resistencia a la hormona presente en la malnutrición, disminuyendo la posibilidad de acción de STAT5 sobre el receptor. Adicionalmente, la distribución ubicua y la expresión tejido-específica de los ARN mensajeros de los genes SOCS observadas en un trabajo previo (22) podría justificar su función como supresores de la señalización, encargados 
de mantener el balance de las vías de señalización activadas por citocinas, en muchas de las cuales es necesaria la acción conjunta de los genes SOCS. Sin embargo, debido a la complejidad del proceso de inactivación y de desensibilización presentes en la señalización de la hormona de crecimiento, al igual que en otras citocinas, se requieren más estudios para determinar los mecanismos de acción de estos genes.

\section{Agradecimientos}

Los autores expresan su agradecimiento a Kjell Malmlof, de Pharmacia, Estocolmo, Suecia, por la colaboración en el desarrollo del protocolo animal. Este trabajo fue financiado por Colciencias y el Programa Internacional en Ciencias Químicas, IPICS, Universidad de Uppsala, Suecia.

\section{Referencias}

1. Cohick WS, Clemmons DR. The insulin-like growth factors. Annu Rev Physiol 1993;55:131-55.

2. Carter Su C, Schwartz J, Smit L. Molecular mechanism of growth hormone action. Annu Rev Physiol 1996;58: 187-207.

3. Lobie PE, Wood TJ, Sliva D, Billestrup N, Waters MJ, Enberg B, et al. The cellular mechanism of growth hormone signal transduction. Acta Paediatr 1994;406 (suppl):39-46.

4. Davey H, Wilkins R, Waxman D. STAT5 signaling in sexually dimorphic gene expression and growth patterns. Am J Hum Genet 1999;65:959-65.

5. Sun H, Tonks NK. The coordinated action of protein tyrosine phosphatases and kinases in cell signaling. Trends Biochem Sci 1994;19:480-5.

6. Yu CL, Burakoff SJ. Involvement of proteasomes in regulating Jak-STAT pathways upon interleukin-2 stimulation. J Biol Chem 1997;272:14017-20.

7. Adams TE, Hansen JA, Starr R, Nicola NA, Hilton DJ, Billestrup N. Growth hormone preferentially induces the rapid, transient expression of SOCS 3, a novel inhibitor of cytokine receptor signaling. J Biol Chem 1998;273: 1285-7.

8. Maes M, Underwood LE, Ketelslegers JM. Plasma somatomedin $\mathrm{C}$ in fasted and refed rats: close relationship with changes in liver somatogenic but not lactogenic binding sites. J Endocrinol 1983;97:243-52.

9. Boisclair Y, Wang J, Shi J, Hurst K, Ooi G. Role of the suppressor of cytokine signaling 3 in mediating the inhibitory effects of interleukin-1ß on the growth hormonedependent transcription of the acid-labile subunit gene in liver cells. J Biol Chem 2000;275:3841-7.
10. Sanchez-Gomez M, Malmlof K, Mejia W, Bermudez A, Ochoa MT, Carrasco-Rodriguez S, et al. Insulinlike growth factor-I, but not growth hormone, is dependent on a high protein intake to increase nitrogen balance in the rat. Br J Nutr 1999;81:145-152.

11. Carrasco de Rodríguez S. Expresión de los genes del receptor de la hormona de crecimiento y del factor de crecimiento similar a la insulina tipo I bajo restricción proteica (tesis). Bogotá: Universidad Nacional de Colombia; 2000.

12. Daughaday W, Kapadia M, Mariz I. Serum somatomedin binding proteins: physiologic significance and interference in radioligand assay. $\mathrm{J}$ Lab Clin Med 1987;109:355-63.

13. Zor T, Selinger Z. Linearization of the Bradford protein assay increases its sensitivity: theoretical and experimental studies. Anal Biochem 1996;236:302-8.

14. Hunter W, Greenwood F. A radio-immunoelectrophoretic assay for human growth hormone. Biochem J 1964;91:43-56.

15. Ranke M, Stanley C, Tenore A, Rodbard D, Bongiovanni A, Parks J. Characterization of somatogenic and lactogenic binding sites in isolated rat hepatocytes. Endocrinology 1976;99:1033-45.

16. Chomczynski P, Sacchi N. Single-step method of RNA isolation by acid guanidinium thiocyanate-phenolchloroform extraction. Anal Biochem 1987;162:156-9.

17. Labarca C, Paigen K. A simple, rapid and sensitive DNA assay procedure. Anal Biochem 1980;102:344-52.

18. Mathews LS, Enberg B, Norstedt G. Regulation of rat growth hormone receptor gene expression. J Biol Chem 1989;264:9905-10.

19. Moller N, Schmitz O, Porksen N, Moller J, Jorgensen JO. Dose response studies on the metabolic effects of a growth hormone pulse in humans. Metabolism 1992;41: $172-5$.

20. Caminos L. Caracterización de clones para el receptor de hormona de crecimiento en linfocitos de rata (tesis). Bogotá: Universidad Nacional de Colombia; 1995.

21. Bermúdez A. Expresión de los genes de IGF-I y receptor de hormona de crecimiento: estudio de linfocitos de sangre periférica de rata bajo condiciones de restricción nutricional proteínico-calórica (tesis). Bogotá: Universidad Nacional de Colombia; 1994.

22. Umaña-Pérez A. Estudio de la regulación por la hormona de Crecimiento de la expresión de los genes SOCS (tesis). Bogotá: Universidad Nacional de Colombia; 1999.

23. Maes M, Ketelslegers J, Underwood L. Low circulating somatomedin $\mathrm{C} /$ insulin like growth factor I in insulindependent diabetes and malnutrition: growth hormone receptor and post-receptor defects. Acta Endocrinol (Copenh) 1986;279(suppl):86-92. 
24. Snyder D, Clemmons D, Underwood L. Dietary carbohydrate content determines responsiveness to growth hormone in energy-restricted humans. J Clin Endocrinol Metab 1989;69:745-52.

25. Clemmons DR, Smith-Banks A, Underwood E. Reversal of diet-induced catabolism by infusion of recombinant insulin-like growth factor-1 in humans. J Clin Endocrinol Metab 1992;75:234-8.

26. Phillips LS. Nutrition, somatomedins and the brain. Metabolism 1986;35:78-87.

27. Underwood L, Thissen J, Lemozy S, Ketelslegers J, Clemmons D. Hormonal and nutritional regulation of IGFI and its binding proteins. Horm Res 1994;42:145-51.

28. Fliesen T, Maiter D, Gerard G, Underwood E, Maes M, Ketelslegers JM. Reduction of serum insulin-like growth factor- 1 by dietary protein restriction is age dependent. Pediatr Res 1989;26:415-9.

29. Thissen J, Triest $\mathbf{S}$, Maes $\mathbf{M}$, Underwood L, Ketelslegers $\mathbf{J}$. The decreased plasma concentration of insulin-like growth factor I in protein-restricted rats is not due to decreased numbers of growth hormone receptors on isolated hepatocytes. J Endocrinol 1990; 124:159-65.

30. Thissen JP, Triest S, Underwood LE, Maes M, Ketelslegers JM. Divergent responses of serum insulinlike growth factor I and liver growth hormone $(\mathrm{GH})$ receptors to exogenous $\mathrm{GH}$ in protein restricted rats. Endocrinology 1990;126:908-13.

31. Thissen JP, Underwood LE, Maiter D, Maes M, Clemmons DR, Ketelslegers JM. Failure of insulin likegrowth factor I (IGF-I) infusion to promote growth in protein-restricted rats despite normalization of serum IGF-I concentrations. Endocrinology 1991;128:885-90.

32. VandeHaar MJ, Moats-Staats BM, Davenport ML, Walker JL, Ketelslegers JM, Shanna BK, et al. Reduced serum concentrations of insulin-like growth factor I (IGF-I) in protein-restricted growing rats are accompanied by reduced IGF-I mRNA levels in liver and skeletal muscle. J Endocrinol 1991;130:305-12.

33. Zhang J, Chrysis D, Underwood L. Reduction of hepatic insulin-like growth factor I (IGF-I) messenger ribonucleic acid (mRNA) during fasting is associated with diminished splicing of IGF-I pre-mRNA and decreased stability of cytoplasmic IGF-I mRNA. Endocrinology 1998;139:4523-30.

34. Thissen JP, Underwood LE. Translational status of the insulin like growth factor I mRNAs in liver of proteinrestricted rats. J Endocrinol 1992;132:141-7.

35. Tirapegui J, Fukushima SE, Grimaldi G. Growth, somatomedin and nutrition. Arch Latinoam Nutr 1993; 43:94-104.

36. Isley WL, Underwood LE, Clemmons DR. Changes in plasma somatomedin $\mathrm{C}$ in response to ingestion of diets with variable protein and energy content. JPEN J Parenter Enteral Nutr 1984;8:407-11.

37. Endo TA, Masuhara M, Yokouchi M, Suzuki R, Sakamoto $\mathbf{H}$, Mitsui $\mathbf{K}$, et al. A new protein containing an SH2 domain that inhibits JAK kinases. Nature 1997; 387:921-4.

38. Starr R, Willson TA, Viney EM, Murray LJ, Rayner JR, Jenkins BJ, et al. A family of cytokine-inducible inhibitors of signalling. Nature 1997;387:917-21.

39. Naka T, Narazaki M, Hirata M, Matsumoto T, Minamoto S, Aono A, et al. Structure and function of a new STATinduced STAT inhibitor. Nature 1997;387:924-9.

40. Starr R, Hilton DJ. SOCS: suppressors of cytokine signalling. Int J Biochem Cell Biol 1998;30:1081-5.

41. Nicholson SE, Hilton DJ. The SOCS proteins: a new family of negative regulators of signal transduction. $J$ Leukoc Biol 1998;63:665-8.

42. Tollet-Egnell P, Flores-Morales A, Stavreus-Evers A, Sahlin L, Norstedt G. Growth hormone regulation of SOCS2, SOCS3 and CIS messenger ribonucleic acid expression in the rat. Endocrinology 1999;140:3693-704. 